\title{
Article
}

\section{Sexual exploitation in children: Nature, prevalence and distinguishing characteristics reported in young adulthood}

Ireland, Carol Ann, Alderson, Kirsty and Ireland, Jane Louise

Available at http://clok.uclan.ac.uk/14076/

Ireland, Carol Ann ORCID: 0000-0001-7310-2903, Alderson, Kirsty and Ireland, Jane Louise ORCID: 0000-0002-5117-5930 (2015) Sexual exploitation in children: Nature, prevalence and distinguishing characteristics reported in young adulthood. Journal of Aggression Maltreatment and Trauma, 24 (6). pp. 603-622.

It is advisable to refer to the publisher's version if you intend to cite from the work. http://dx.doi.org/10.1080/10926771.2015.1049765

For more information about UCLan's research in this area go to http://www.uclan.ac.uk/researchgroups/ and search for <name of research Group>.

For information about Research generally at UCLan please go to http://www.uclan.ac.uk/research/

All outputs in CLoK are protected by Intellectual Property Rights law, including Copyright law. Copyright, IPR and Moral Rights for the works on this site are retained by the individual authors and/or other copyright owners. Terms and conditions for use of this material are defined in the policies page.

\section{CLoK}

Central Lancashire online Knowledge www.clok.uclan.ac.uk

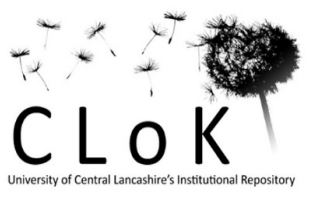


Running head: SEXUAL EXPLOITATION IN YOUTH

Sexual exploitation in children: Nature, prevalence and distinguishing characteristics reported in young adulthood

Carol A. Ireland

Ashworth Research Centre, Mersey Care NHS Trust, School of Psychology, University of Central Lancashire, UK and CCATS: Coastal Child and Adult Therapeutic Services, UK

\author{
Kirsty Alderson \\ HMP Risley, HM Prison Service and University of Central Lancashire, UK
}

Jane L. Ireland

Ashworth Research Centre, Mersey Care NHS Trust, University of Central Lancashire, UK

Key words: Exploitation, Sexual Abuse, Vulnerability, Nature, Extent, Self-Esteem, Attachment 
Sexual exploitation in children: Nature, prevalence and distinguishing characteristics reported in young adulthood

\begin{abstract}
The aim of this study was to explore the nature and extent of sexual exploitation in a university student sample, whilst being clear that sexual exploitation is sexual abuse. Overall, $47 \%$ of participants (96 out of 204) reported having been approached by an adult in a sexual manner when they were under the age of 16 . The study predicted that a number of individual characteristics would increase a young person's vulnerability for sexual exploitation. These included low self-esteem, external locus of control, social loneliness and insecure attachment. Results indicated lower levels of self-esteem among those who had been approached sexually, although it is not clear in terms of causality. There were no differences in scores for locus of control or loneliness. Relationship anxiety was significantly linked with children having engaged in sexual behaviours with an adult. The implications of these findings are discussed in terms of emerging individual characteristics relating to a risk of sexual exploitation.
\end{abstract}

Key words: Exploitation, Sexual Abuse, Vulnerability, Nature, Extent, Self-Esteem, Attachment 


\section{SEXUAL EXPLOITATION IN YOUTH}

Sexual exploitation in children: Nature, prevalence and distinguishing characteristics reported in young adulthood

Sexual exploitation is regarded as a form of sexual abuse (DCSF, 2009, Barnardos, 2012) and where perpetrators aim to develop a relationship with the child, with the intention of committing a sexually abusive act. As such, it is regarded as interchangeable with the term sexual abuse. It frequently involves children being expected to 'swap' sex or sexual behaviours in exchange for a range of goods. These include affection, food, accommodation, drugs or gifts (Barnardos, 2011). Some children may view the exchange of sex as a means to provide for basic needs. These needs are often present due to a range of social difficulties, including maladjustment in the home or instability with care provision (Coy, 2008). The sexual abuse involves an imbalance of power between the victim and perpetrator, limiting the options available to the victim, and which can be misunderstood by victims and outsiders as consensual (Barnardos, 2012). Yet, it is clearly an act of sexual abuse and would have parallels to other forms of sexual abuse, such as that perpetrated within the family home and where there can also be an imbalance of power and provision of basic need. Therefore, the term sexual abuse and exploitation will be used interchangeably in this paper, with sexual abuse being the broader term. It can further be difficult to offer a clear definition of sexual exploitation that is distinctly different to what may be seen by others as a clear act of sexual abuse. . Fundamentally it all refers to sexually abusive behaviours; the challenges in understanding sexual exploitation in this way may be due more to individuals wrongly regarding it as a consensual act as opposed to its correct recognition as a form of sexual abuse.

Sexual exploitation does not always involve physical contact between a child and perpetrator. For example some children are exploited using technology such as mobile telephones or the internet (Barnardos, 2012), such as through Facebook. Through these types 


\section{SEXUAL EXPLOITATION IN YOUTH}

of technology children may be exposed to sexual images or materials, or be involved in the production of indecent images (Beckett, 2011). It is not yet clear as to any differing dynamics between young people exploited via the internet, and those more directly through face to face contact. Often it can be noted that a variety of forums may be used to conduct such sexual abuse, and which can be used interchangeably. Children of all ages are targeted by perpetrators, but those aged 13 to 17 have been highlighted as most at risk (Jago, Arocha, Brodie, Melrose, Pearce \& Warrington, 2010; Wolak, Finkelhor, Mitchell \& Ybarra, 2008). When a perpetrator targets a child they may initially show kindness and affection. As a result many children do not realise they are being groomed for sexual abuse (Barnardos, 2011; Phoenix, 2012). Some perpetrators also use violence, coercion, threats and intimidation to secure compliance (Barnardos, 1998; Barnardos, 2011 Jago, 2010). These strategies are often used to force children to engage in sexual activity with a perpetrator's friends or associates (Barnardos, 2011).

Much of the research into sexual exploitation has focussed on the pathways into such sexual abuse (Barnados, 2004; Coy, 2009; Jago et al, 2010; Swann, McNosh \& Edwards, 1998; Taylor-Browne, 2002), and the vulnerability factors that are present in those who are sexually exploited. These include prior experiences of sexual abuse, poor parenting or maladjustment in the home (drugs, alcohol, violence), a history of residential care, friends' involvement in sexual exploitation, having run away from home, truanting, drug/alcohol use and homelessness (Barnardos, 2011; Beckett; 2011; Coy, 2009; Cusick, 2002; Cusick, Martin \& May, 2003; Jago et. al., 2010; Lebloch \& King, 2006; Pearce, Williams \& Galvin, 2002). . To date there has been little examination of the individual characteristics of those who have experienced childhood sexual exploitation, including how children can respond to this form of abuse.

Prevalence of sexual abuse is further noteworthy, and in additional respect of gender. For instance, Ashcroft, Daniels and Hart (2003) noted that girls ages 12 to 17 years were at 


\section{SEXUAL EXPLOITATION IN YOUTH}

greater risk of sexual abuse than boys (13\% versus 3.4\%). In their research of 326

adolescents who had experienced sexual assault, 74\% knew their perpetrator, such as family members and friends (Ashcroft et al, 2003). In the U.S., studies show that one in four girls and one in six boys are sexually abused before 18 years of age (Finkelhor, Hotaling, Lewis \& Smith, 1990). Yet, it must always be considered that boys may underestimate due to stigma, including amongst others unfounded beliefs that males are rarely sexually assaulted and male victims are somehow responsible for the abuse (Bullock \& Beckson, 2011).

In order to identify the potential impact of this type of sexual abuse, it will be useful to review findings that relate to the outcomes of childhood sexual abuse in general. As part of this, further consideration is needed in regard to the impact of being exposed to multiple forms of victimization (polyvictimization). For example, Finkelhor, Ormrod and Turner (2007) considered this in their longitudinal research, looking at a sample of children ages 2 to 17 years. Eighteen percent of the children studied experienced at least four different kinds of victimization in the last 12 months. Such multiple types of victimization were highly predictive of trauma symptoms at the end of this 12 month period, even when prior victimization and mental health were controlled for. As such, they presented a convincing argument that it is multiple forms of victimization that have a more substantial impact than when reviewing individuals episodes of victimization. Outside of this, children can respond to sexual abuse in a number of ways, with some presenting as having no adverse symptoms (Finkelhor \& Berliner, 1995). It has been suggested that this could be due to a range of factors, including resilience, a delayed onset of symptoms, avoidance, or that a child is experiencing symptoms that have not yet been identified (Finkelhor \& Berliner, 1995). It may also be that these victims have not been exposed to multiple different types of victimization, and as noted in Finkelhor et al's (2007) work above on polyvictimization. Similarly, individuals who have experienced sexual exploitation during childhood may appear to be functioning normally in life. Yet, this experience may have impacted on the 


\section{SEXUAL EXPLOITATION IN YOUTH}

development of certain attitudes or beliefs that are not immediately evident to the observer. For example attitudes towards the self, the world or others are likely to cause significant problems during adulthood for those who have been exploited. The traumagenic model of sexual abuse could support this claim (Finkelhor \& Browne, 1985) and would be considered a seminal piece. This explanatory model was developed from research into the varied outcomes observed among those who have experienced sexual abuse. The model proposes four primary effects of sexual abuse: traumatic sexualisation, stigmatisation, betrayal and powerlessness. Stigmatisation is thought to result in feelings of isolation and impact on victims' self-esteem. Betrayal is thought to impact on relationships, with victims experiencing either a lack of trust towards others or focussing on attaining a 'redeeming relationship' during adulthood. It is proposed that powerlessness distorts an individual's perceptions of control over life events. An overview of the research upon which this model is based will be presented, focussing on findings which could be reasonably applied to those who have experienced sexual exploitation.

Low self-esteem has been observed among those who have experienced sexual abuse (Conte \& Schuerman, 1987; Finkelhor, 1990). Abusive experiences are thought to impact on a victims' self-concept as some engage in self-blame when making sense of these experiences. For example they may hold themselves responsible for the abuse (Dimock, 1988; Jehu, 1988) or blame themselves as they did not resist the approach of a perpetrator (Cahill, Llewelyn \& Pearson, 1991). Negative self-perceptions are also thought to rise from the stigmatisation of child sexual abuse victims by the abuser and society (Briere \& Elliot, 1994). This stigma is thought to be even more pronounced among those who have been sexually exploited (Kelly, Wingfield, Burton \& Regan, 1995). This may be because some children are perceived by some adults as having consented to the abuse (Smeaton, 2013).

It is not just self-concept that is affected however, other consequences of childhood sexual abuse include social isolation and poor social adjustment (Gibson \& Hartshorne, 


\section{SEXUAL EXPLOITATION IN YOUTH}

1996; Harter, Alexander, \& Neimeyer, 1988). Children who have been sexually abused are observed to be less socially competent, more socially withdrawn and perceive themselves as different to others when compared with non-abused children (Briere \& Elliot, 1994). Based on these findings it would be reasonable to assume that intimate relationships are also affected. The research supports this, with difficulties in both partner and peer relationships being observed among those who have been sexually abused (Aspelmeier, Elliott \& Smith, 2007; Carr et. al., 2010; Colman \& Widom, 2004; Finkelhor, 1990). Individuals who have experienced sexual exploitation may also experience difficulties building emotionally intimate relationships during adulthood. Attachment Theory (Bowlby, 1969; Bartholomew \& Horowitz, 1991) may explain this. During infancy and childhood individuals learn how to relate to others in the context of a relationship. Experiencing sexual exploitation during this key developmental period may significantly impact on this process. For example some children initially believe they are in a relationship with a perpetrator. Their views may change as they move into adulthood and begin to make sense of this experience. It is possible that individuals may doubt the intentions of a partner or feel less able to trust another if they come to realise their childhood experiences were exploitative in nature. For example children who are sexually exploited are thought to experience a disruption of trust due to experiencing different forms of manipulation by a perpetrator (Kelly et. al, 1995). It is also worthy to note that there can be protective factors which can buffer against the negative impact of sexual abuse. Dufour et al (2000) note that between $20 \%$ and $44 \%$ of adults who experienced sexual abuse in childhood demonstrated no apparent negative consequence. Furthermore, they observed the use of social support after the abuse appeared to be a positive factor in experiencing less psychological distress, whereas avoidance of the difficulties had a negative impact, irrespective as to how useful the victim felt such a strategy to be. Additional research has suggested that the sooner the abuse is discussed the better the mental health outcome (Lamb \& Edgar-Smith, 1994; Paine \& Hansen, 2002). 


\section{SEXUAL EXPLOITATION IN YOUTH}

Sexual abuse not only impacts on attitudes toward the self and others, but it can also influence how individuals perceive the world. It has been argued that feelings of powerlessness as a result of sexual abuse distorts a child's belief in their ability to control their own life (Finkelhor \& Browne, 1985; Finkelhor, 1987). It is thought that this link exists because the abuse occurred when a child was physically or psychologically unable to resist the abuse (Briere \& Elliot, 1994). Whilst being sexually exploited, a child may exchange sex or sexual behaviours in order to improve their circumstances, where needs for food, stable accommodation or affection are not being met. It is possible that these experiences may contribute to a feeling of limited control over events or circumstances in their life.

Consequently, a more external locus of control may be observed among those who have been sexually exploited during childhood. Children who have been maltreated during childhood, including being sexually abused, have reported an external locus of control (Moran \& Eckenrode, 1992). However, not all of the comparison group in the cited study had experienced childhood sexual abuse. As such, the relationship between sexual abuse and locus of control is unclear. It is important to note that the sexual abuse research cited in this article is not recent. It would appear that interest in this area has decreased during the past 15 years. It is not clear whether this research remains relevant or whether the findings apply to all forms of sexual abuse, including sexual exploitation.

Whilst it is important to identify the individual characteristics of those who have experienced sexual exploitation, research must also aim to understand the extent of the problem. There are many difficulties in establishing the nature and extent of sexual exploitation. Estimates are often based on how many children access specialist support services, or services for substance and or alcohol use (Stredder, Woolfall, Gray \& Sumnall, 2009). Figures obtained in this way are not representative as many children who are exploited may not access support. This is evidenced by the common finding that exploitation is often not reported by children (Warrington, 2010). This may be because many children 


\section{SEXUAL EXPLOITATION IN YOUTH}

are afraid of retribution by the perpetrator, they experience a mistrust of adults or agencies (Barnardos, 2004; Cusick, 2002) or they do not recognise they are being sexually exploited (Phoenix, 2012). Estimates also rely on professionals being able to recognise signs of sexual exploitation. It is often difficult to identify, as some of the methods employed by perpetrators involve creating distance between the young person and service providers, caregivers and friends (Jago, 2010).

An overall critique of current research is that, despite frequently concluding that the nature and extent of sexual exploitation is a neglected area, few articles focus on measuring this directly. This study is hoping to go some way to begin to address this issue. The purpose of the present study is to explore self-reported childhood sexual exploitation in a young adult sample. Sexual exploitation will be explored among university students, asking them to consider their experiences when they were under the age of 16. A student sample was felt most helpful as it allowed some access to a general sample of young people, although understandably only one part of the general population of young people. It was hypothesised that participants who experience social loneliness would be more likely to report having prior experience of sexual exploitation before the age of 16. Those with a more external locus of control, those with a less secure style of attachment and those with lower self-esteem, would also be more likely to report having experienced sexual exploitation.

\section{Method}

\section{Participants}

One hundred and ninety eight university students took part in the study. Males represented $25.8 \%$ of the sample $(n=51)$ and females $72.7 \%(n=144)$, with $1.5 \%$ not reporting gender $(n=3)$. The mean age of participants was $20.18(\mathrm{SD}=2.37)$. Younger adults were targeted for the study as a number of questions related to experiences of sexual exploitation on the internet and mobile telephones, reflecting the nature and extent of sexual exploitation that has taken place primarily within the last 10-15 years. The majority of the 


\section{SEXUAL EXPLOITATION IN YOUTH}

sample described themselves as White British ethnic origin $(78 \%, \mathrm{n}=159)$ and the remainder of the sample described themselves as White Irish $(1 \%, n=1)$, White other $(3 \%, n=6)$ Asian $(13.5 \%, n=27)$, Black African $(.5 \%, n=1)$, Black Other $(.5 \%, n=1)$, Mixed $(3 \%, n=6)$ and Other $(.5 \%, \mathrm{n}=1)$. One participant did not report their ethnic origin. These are very similar to the figures obtained in the 2011 census (ONS, 2012).

\section{Measures}

A number of measures were used. These were as follows:

Checklist to assess sexual exploitation: This measure was designed by the researchers to examine the nature and extent of sexual exploitation. Experiences which comprise sexual exploitation were based on definitions within the available literature and were reviewed by the research team who had specific clinical expertise in working with young people who had been sexually exploited. The items were also reviewed by clinicians outside of the research team, and who work directly in the field of sexual exploitation. This checklist examines the experiences of participants when they were under the age of 16. The response format varies, with some requiring a response of either yes/no, some requiring written input and a selection of several pre-determined options. Example of one of the questions is:

(1) Below the age of 16, did you ever feel you were expected to perform sexual acts as a result of someone you believed to be over the age of 18 giving you gifts (jewellery, mobile phone, clothes, money)?

As noted in the example above, this checklist explores a range of sexually inappropriate behaviours, including a young person being approached by an adult to engage in sexual behaviour in response to a range of interactions. This can include the adult buying them gifts, drugs, providing accommodation, and where they were then expected to engage in such sexual acts. This checklist requests indication as to whether they engaged in such requests and their feelings in response to this. The sample were then able to be grouped in to those who were not approached in a sexually inappropriate manner, those who were approached but did not engage, 
SEXUAL EXPLOITATION IN YOUTH

and those who were approached and did engage. From this, participants were also asked to note their actual age at the time, the perceived age and then actual age of the adult perpetrator.

The Revised UCLA Emotional Loneliness Scale (Russell, Peplau \& Cutrona, 1980): This

scale measures current social loneliness. It comprises of 20 items, and the response format is a 4-point likert scale. Example items include "How often do you feel you lack companionship?" and "How often do you feel outgoing and friendly?". Responses range from 'never' to 'always', with no neutral response option. Higher scores indicate a greater degree of loneliness. Internal consistency has been assessed, with coefficient $a$ ranging from .89 to.94 and test-retest reliability over a 1-year period was $r=.73$ (Russell, 1996).

The Locus of Control of Behaviour Questionnaire (Craig, Franklin \& Andrews, 1984): This is an 18-item questionnaire, designed to assess the degree to which individuals view events as being either within or outside of their control. Example items include "Other people do not control what happens to them" and "When I aim to do something, I do it". The response format is a 5-point likert scale, with responses ranging from 'always disagree' to 'always agree'. Higher scores indicate a more external locus of control. Internal consistency has been assessed, with coefficient $a$ of .79 and test-retest reliability over a 6 month period was $r=.73$ (Craig et al, 1984).

The Self-esteem Scale (Rosenberg, 1965): This is a 10-item questionnaire that is designed to assess self-worth/self-image. Example items include "At times, I think I am no good at all” and "I feel I do not have much to be proud of". This is a 4-point likert scale; with responses ranging from strongly agree to strongly disagree. Higher scores indicate higher levels of self-esteem. Internal Consistency has been assessed, with Cronbach's alpha ranging from .77 to .88 . Test-retest Reliability ranges from .82 to .88 (Rosenberg, 1965).

\section{Experiences in Close Relationships-Revised (ECR-R) Adult Attachment Questionnaire}

(Fraley, 2000): This is designed to assess individual differences with respect to attachmentrelated anxiety and attachment-related avoidance and participants therefore obtain two 


\section{SEXUAL EXPLOITATION IN YOUTH}

overall scores. Example items include "I'm afraid that I will lose my partner's love" and "I prefer not to show a partner how I feel deep down". Each item is rated on a 7-point likert scale with responses ranging from strongly disagree to strongly agree. Higher scores on each sub-scale indicate a greater degree of anxiety and avoidance. Participants were advised not to complete this questionnaire if they had no previous experience of a partner type relationship. Thirty participants did not complete the questionnaire. Internal reliability has been assessed, with Cronbach's alpha 0.95 on the anxiety sub-scale and 0.93 on the avoidance sub-scale (Sibley \& Liu, 2004).

\section{Procedure}

All participants were approached by the researcher on the University campus for recruitment to the study. As agreed by ethics, they were approached randomly outside lectures and in the main canteens. An information sheet was provided, detailing the nature of the study and to determine their willingness to take part. Information was provided about the study on this information sheet as follows:

"I want to explore people's experiences of having been approached by an adult in a sexual manner whilst under the age of 16, either through the internet, in person or by mobile telephone. I am also interested in personal factors, such as self-esteem and attachment style among those who have been approached by an adult in a sexual manner. If you could spare 25 minutes of your time to complete the following questionnaires I would be very grateful".

It was indicated that participation was anonymous and they were under no obligation to complete the study. Upon consenting, a copy of the questionnaire pack was given to each participant. Completed packs were returned to the researcher at a designated secure location on the university campus. Participants were not required to record personal details on the questionnaires. All participants were provided with a debrief sheet at the end of the questionnaire pack. Of those that consented to engage in the research, there was a $45 \%$ return rate. 


\section{Results}

Missing data was assessed and the results indicated that data was missing completely at random. There were only 29 data points missing across the data set, missing from 24 participants; most missed one item only. Missing data was replaced with group means, as suggested by Tabachnick \& Fidell (2007). Scores for each participant were then summed and univariate outliers were identified by calculating the outlier labelling rule for each dependent variable (Hoaglin \& Iglewicz, 1987). One univariate outlier was identified and amended. No multivariate outliers were identified in the data. Normality was assessed for each variable through inspection of descriptives, skewness and kurtosis values and these revealed that data was normally distributed.

Internal reliability was assessed for each scale. For the self-esteem scale coefficient $a$ was 0.91 . The locus of control scale produced an alpha of 0.80 . The loneliness scale produced an alpha of 0.30 and for the ECR-R an alpha of 0.82 . As such, the internal reliability for the loneliness scale should be regarded with caution, although reliabilities for the other scales were acceptable to very good. The data was then analysed using ANOVA and Multinomial Logistic Regression.

Nature and extent of sexual exploitation: Overall, 46.9\% of participants (93 out of 198) reported having been approached by an adult (an individual aged 18 and over) in a sexual manner when they were under the age of 16 . Table 1 shows the gender of those who were approached sexually and highlights those who subsequently engaged in sexual behaviours (that is, who were subsequently sexually abused).

\section{[Insert Table 1 here]}

There were a range of different types of sexual approaches made by adults when participants were under the age of 16 years. These are reported in Table 2.

[Insert Table 2 here] 


\section{SEXUAL EXPLOITATION IN YOUTH}

Characteristics across groups: Participants were separated into three groups in order to differentiate between their experiences of sexual exploitation. Group $1(n=105)$ reported never to have been approached sexually by an adult (no experience), Group 2 ( $n=49)$ reported being approached in a sexual way yet avoided sexual exploitation (experience not exploited) and Group $3(\mathrm{n}=44)$ reported having been approached in a sexual way by an adult and they had subsequently been sexually exploited (experience successfully exploited). Locus of control: When the Bonferroni correction was applied, outcome from a one way ANOVA was not significant when examining the impact of sexual exploitation on scores for the locus of control scale, $F(2,191)=3.57, p>.013(p=.03)$. This indicated there were no differences in locus of control for participants, regardless of their experience of sexual exploitation.

Self-esteem: A one way ANOVA demonstrated an overall effect of sexual exploitation on self-esteem, $F(2,191)=6.20$, p $\prec .005$. Having some experience of being approached sexually by an adult impacted on scores for the self-esteem scale compared to not having been sexually approached by an adult $t(191)=-3.46$, p $<.005$. This indicated that participants who had been previously approached sexually by an adult had lower levels of self-esteem than those who had not been approached. There were no differences in self-esteem when participants who had successfully been exploited by an adult were compared with those who avoided exploitation following an approach $t(191)=-.74$, p .05 .

Loneliness: There were no significant differences between groups with regard to loneliness, $\mathrm{F}(2,191)=2.49, \mathrm{p}>.05$

\section{[Insert Table 3 here]}

$\underline{\text { Relationship style: Multinomial logistic regression was undertaken in order to predict }}$ experience of being approached sexually by an adult based on relationship style. Participants were separated into three groups: (1) those with no experience of being approached sexually, (2) those with experience yet were not exploited and (3) those with experience who were 


\section{SEXUAL EXPLOITATION IN YOUTH}

successfully exploited. A test of the full model with both predictors against a constant only model was statistically significant, $\chi_{2}(4, \mathrm{n}=168)=28.72, \mathrm{p}<.001$. This indicated that relationship style reliably distinguished between individuals who had been approached sexually by an adult under the age of 16 and those who had not. There was a good model fit $\chi_{2}(316, \mathrm{n}=168)=312.17, \mathrm{p}=.55$, using a deviance criterion Nagelkerke $\mathrm{R}_{2}=.18$

Comparisons of log likelihood ratios showed a significant improvement with the addition of relationship anxiety $\chi_{2}(2)=20.83, p<.001$, meaning that relationship anxiety was higher among those who had been sexually exploited, compared with participants who had not been approached at all. When the Bonferroni correction was applied, there was no significant improvement with the addition on relationship avoidance, $\chi^{2}(2)=8.31, \mathrm{p}>.013(\mathrm{p}=.016)$.

On the basis of both predictors, correct classification rates were $85.4 \%$ for Group 1 (no experience), 26.2\% for Group 2 (experience not responded) and 27.3\% for Group 3 (experience and responded). Regarding individual predictors, relationship anxiety separated participants who had no experience of being approached sexually by an adult and those who had been approached and subsequently responded sexually, $b=-0.04$, Wald $\chi^{2}(1)=13.06$, $0<.001$. No predictor separated participants who had been approached sexually and subsequently engaged in sexual behaviours, and those who did not engage.

\section{Discussion}

Almost half of the sample reported to have been approached by an adult in a sexual manner when they were under the age of 16 , and which should be noted as a high figure that is worthy of further consideration. Although no statistical analysis was undertaken, it would appear simply from percentages in Table 1 that more females were approached sexually than males; further statistical analysis is however required. Over one fifth of the sample were successfully exploited following an approach by a perpetrator. The internet, along with mobile telephones, were the most frequently reported method of approach used by adults, showing how these forms of technology were a clear avenue to perpetrate sexual abuse. 


\section{SEXUAL EXPLOITATION IN YOUTH}

Using these methods, perpetrators were most likely to make sexual suggestions to children and encourage them to engage in sexual discussions. This finding is likely to reinforce concerns with regard to these forms of technology being used to sexually exploit children.

This is likely to be of particular concern to caregivers and young person's charities due to the difficulties in monitoring children's internet use, particularly outside of the home. It is not possible to accurately determine the nature of the relationship between the victim and perpetrator in this study. However, the view would be that it is a relationship where the perpetrator is attempting to befriend the victim as opposed to a family member. This would be due to the main methods of contact by the perpetrator not being indicative of an individual who is part of the family home, such as attempting to access the victim through the internet and mobile phones. This is however something that will be considered in later studies.

Contrary to expectations, there was no difference in self-esteem between those who were sexually exploited and those who had managed to avoid being exploited. This is at odds with the research on the outcomes of child sexual abuse (CSA), and which frequently highlights lower self-esteem among those who have experienced sexual abuse during childhood (Conte \& Schuerman, 1987; Finkelhor, 1990). This is thought to result from negative self-attributions and self-blame (Dimock, 1988; Jehu, 1988). Although means were in the direction expected in this study, it is possible that there are protective factors that have not been examined that have minimised the impact of sexual exploitation on self-esteem. For example, the study did not examine the influence of positive social support or determine if such abuse had been disclosed and positively responded to; all of which has been noted to less negative outcome for a victim in the longer term. For example, researchers have identified other factors that contribute to the negative outcomes observed in those who have experienced sexual abuse. These generally relate to family dysfunction and lack of a supportive environment (Bhandari, Winter, Messer, \& Metcalfe, 2011; Romans, Martin, \& 


\section{SEXUAL EXPLOITATION IN YOUTH}

Mullen, 1997). Alternatively, it may be that those who have experienced sexual abuse may not have experienced multiple types of victimization: polyvictimization (Finkelhor et al, 2007). Therefore the impact may potentially be less in regard to self-esteem, possibly explaining why significance was not met. Whilst this study did not control for polyvictimization, it may be that within the data set of this sexually abused group there are those that have been exposed to multiple types of victimization. As such, future research would need to be consider this as a group in its own right. Yet, and as expected, results did indicate that young adults who had been approached sexually by an adult during their childhood, did in fact experience lower levels of self-esteem compared with those with no experience at all. Consequently, self-esteem could actually be related to whether a child is initially approached by an adult. It is therefore possible that low self-esteem is exhibited through an individual's presentation or is evident in their interactions with others. If this is the case it could be argued that a perpetrator is able to identify these signs and may interpret these as indicators for compliance or vulnerability. Given that some of these children managed to resist the exploitation attempt, other protective factors may have prevented the sexual approach from being successful.

There were no differences in locus of control for participants, regardless of their experience of sexual exploitation. Overall, participants with prior experience of sexual exploitation did not exhibit an external locus of control. Results could indicate that young adults who have experienced childhood sexual exploitation do feel relatively in control of their lives. This does not fit with previous research relating to child sexual abuse, which links this experience with feeling powerless in life (Finkelhor, 1987). Results could indicate that either (1) sexual exploitation is different to other forms of sexual abuse and does not impact on perceptions of control, or (2) other factors in a young person's life contribute to a more internal perception control and which may even have come after the abuse. For example according to Finkelhor \& Browne (1985), experiences before and after sexual abuse 


\section{SEXUAL EXPLOITATION IN YOUTH}

impact on the severity of negative outcomes. They refer to research that identifies factors such as family environment and how others respond to a victim's disclosure. This would suggest that protective factors potentially exist that minimise some of the negative effects of sexual exploitation.

There were also no differences in scores for loneliness. Overall, those who had experienced sexual exploitation did not exhibit high levels of social loneliness. This finding is also at odds with research into child sexual abuse (Gibson \& Hartshorne, 1996; Harter, Alexander, \& Neimeyer, 1988), where it is argued that some children are socially withdrawn and perceive themselves as different to others following experiences of sexual abuse (Briere \& Elliot, 1994). Results could indicate that individuals who have experienced sexual exploitation do not struggle to relate to others in a social context. It is possible that protective factors exist which lessen the impact of sexual exploitation. Yet, care has to be applied as the loneliness measure presented with low reliability.

Confirming the prediction, young adults with an insecure attachment, specifically high relationship anxiety, experienced sexual exploitation during childhood. Relationship avoidance was not however associated with experience of sexual exploitation. These findings fit with existing research (Aspelmeier, Elliott \& Smith, 2007; Carr et. al., 2010; Colman \& Widom, 2004; Finkelhor, 1990). Individuals with an anxious style of attachment value intimacy to such a degree that they may present as overly dependent. They generally possess less positive views of themselves and seek validation or approval from partners. Results from this study may indicate either (1) relationship anxiety creates vulnerability for sexual exploitation or (2) the experience of having been exploited impacts on how a young person later forms relationships with others. Regarding the first explanation, relationship anxiety could create vulnerability if a child feels undervalued by caregivers at the time of the exploitation attempt. Consequently, they may engage in sexual behaviours as directed by a perpetrator, in order to seek approval or maintain positive regard. Alternatively, exploitation 
SEXUAL EXPLOITATION IN YOUTH

could impact on the development of attachment style when a child begins to make sense of their experience.

Results indicated that children who had been successfully exploited did not differ to children who had avoided the exploitation attempt. It would be reasonable to expect some differences to exist between one group of individuals who are able to avoid exploitation and another group who are successfully exploited. Future research should explore factors that could reliably separate these groups. Consideration should be given to protective factors as well as vulnerability factors. It will be important to examine the decision making process when a young person is first approached by an adult in a sexual manner and also examine what is happening in their lives at that time. Furthermore, it can further observed that it can be difficult to tease out individual characteristics for victims in terms of whether these are vulnerability factors, consequences of sexual exploitation or indeed both.

There are limitations in the current study that highlight future avenues for research. Of crucial consideration is that participants self-select to take part in the study. This can of course question the range of participants. Whilst not a unique issue to this study, it is nonetheless worthy of note and consideration. It can always be helpful for future research to consider how the issue of self-selection can be managed without the risk of coercion. Also, the findings of this study highlight a link between prior experience of sexual exploitation, self-esteem and relationship anxiety among a young adult sample. Clearly, an association is not sufficient to indicate causality. For example, it is not clear if self-esteem is a vulnerability in the risk of being exposed to sexual exploitation, or if it is a factor that could arise post the abuse. This would warrant further investigation. It will further be necessary to examine the individual characteristics and family/care environment of children who have been sexually exploited. This group should be compared with children who have successfully avoided an exploitation attempt. This will enable researchers to separate vulnerability characteristics from outcomes, as low self-esteem and anxious attachment could have been present before 


\section{SEXUAL EXPLOITATION IN YOUTH}

the exploitation attempt. Furthermore, the study did not attend to the issue of polyvictimization, and this is something that should be considered in later studies.

This study did not aim to view individual instances of sexual abuse and their consequent impact, but rather as one main group. There are potentially implications by looking at sexual abuse as one whole in that it is not possible to identify which event may have led to a potentially traumatic response or impacted most significantly on mental health. Yet, and in line with a developing research body on polyvictimization, there is perhaps an even greater need to examine multiple types of abuse, as opposed to singular instances.

There are further potential restrictions in asking participants to consider experiences that took place a number of years previously; in this instance asking young adults to consider experiences when they were under the age of 16 years. Yet, one of the challenges when discussing sexual exploitation in children directly is a difficulty in them acknowledging and then discussing such abuse. This can be due to a variety of reasons, such as not believing it to be abuse, fear of harm if they discuss their abuse, along with a lack of trust (Barnardos, 2004; Cusick, 2002, Phoenix, 2012). As such, it could be argued that asking a young adult to reflect on their experiences when under the age of 16 may then allow a period of reflection and to maximise an ability where they feel more able to be truthful in their responses.

Finally, there was a much smaller sample of males in the study than females, and which would need to be addressed in future research. It is hard to predict why there was a substantially smaller sample of males without presenting as speculative. It may be speculated that the level of sexual abuse is reported to be lower in men, as noted by Ashcroft, Daniels and Hart (2003), and they may simply have made a decision not to complete the measures. Alternatively, there continues to be a stigma attached to male sexual assault, and as described earlier by Bullock \& Beckson (2011). Here, even the completion of anonymised research measures may prove difficult for such male participants to complete, and they could potentially choose to then disengage from the study. At this stage however, such arguments 


\section{SEXUAL EXPLOITATION IN YOUTH}

are purely speculation, yet this discrepancy in return rate based on gender clearly warrants further investigation. In terms of representativeness of the sample relating to ethnicity, the sample was very similar to the figures obtained in the 2011 census (ONS, 2012). In terms of gender, it was less representative of male participants in terms of the universities male to female ratio, with more female participants completing the study. Outside of this can be a further consideration that the research could have been considered to have lead-in questions. For instance, the study asked about experiences of being approached by an adult in a sexual manner, and if some participants had not been approached in this way, may have felt the study was not directed toward them, and may have then opted out.

The current study also has a number of strengths. Much of the existing research into sexual exploitation has focussed on children who have experienced significant maladjustment during childhood. They have chiefly been identified as a result of coming into contact with children's or young person's agencies. It could be argued that the current study offers information on a group of individuals who may not be viewed as typically vulnerable: they are drawn from a student rather than a clinical sample. It is inappropriate however to make inferences about the lives of participants in this study without having explored life histories in any detail. It will be useful for future research to examine whether certain characteristics enable some children to cope with negative and traumatic life experiences, which includes maladjustment in the home and sexual exploitation. A range of attitudinal factors that influence attitudes and decision making should also be explored. This will help to develop our understanding of the individual difference characteristics that increase vulnerability for sexual exploitation.

This study also provides current figures on the nature and extent of sexual exploitation that has taken place during the previous 10 years among a young adult student sample. This study aimed to ensure appropriate representation from males and females and 


\section{SEXUAL EXPLOITATION IN YOUTH}

the wide range of ethnicities that make up the UK population. This would maximise the generalisability of findings from the study. Equal representation was not achieved in the current study and future research should aim to target males, first identifying potential barriers to engagement and identifying strategies to overcome these. Future research should also aim to explore the circumstances of exploitation attempts in order to understand whether experiences differ for individuals depending on their gender and ethnicity, as suggested by Ward \& Patel (2006). This should also look to explore in detail any differences in terms of the nature of the sexual exploitation, such as using the internet versus mobile phones This will ensure that models of sexual exploitation that are developed can be applied to a heterogeneous group. It is vital that understanding is not developed solely from studies involving predominantly white female participants.

\section{References}

Ashcroft, Daniels and Hart (2003). Research in Brief: Youth Victimization: Prevalance and Implications, US Department of Justice.

Aspelmeier, J. E., Elliott, A. N., \& Smith, C. H. (2007). Childhood sexual abuse, attachment, and trauma symptoms in college females: The moderating role of attachment. Child Abuse \& Neglect, 31, 5, 549-566.

Barnardos (1998) Whose Daughter Next? Children abused through Prostitution. Barnardo's, London.

Barnardos (2004). Scratching the Surface: what we know about the abuse and sexual exploitation of children by adults targeting residential and supported accommodation units. Glasgow: Barnardos.

Barnardos (2011). Puppet on a String: The Urgent Need to Cut Children Free from Sexual Exploitation. Barnardos: Essex.

Barnardos (2012). Cutting them free: how is the UK progressing in protecting its children from sexual exploitation? Barnardos: Essex. 
SEXUAL EXPLOITATION IN YOUTH

Bartholomew, K., \& Horowitz, L. M. (1991). Attachment styles among young adults: a test of a four category model. Journal of Personality and Social Psychology, 61, 2, 226244.

Beckett, H. (2011). Not a world away: The sexual exploitation of children and young people in Northern Ireland. Barnardos: Northern Ireland.

Bhandari, S., Winter, D., Messer, D., \& Metcalfe, C. (2011). Family characteristics and long term effects of childhood sexual abuse. British Journal of Clinical Psychology, 50, $435-451$.

Bowlby, J. (1969). Attachment and Loss: Volume 1: Attachment. London: The Hogarth Press and the Institute of Psycho-Analysis.

Briere, J. N., \& Elliot, D. M. (1994). Immediate and long term impacts of child sexual abuse. Sexual Abuse of Children, 4, 2, 54-69.

Bullock, C.M. and Beckson, M (2011). American Academy Psychiatry and Law, 39 (2),197 $-205$.

Cahill, C., Llewelyn, S. P., \& Pearson, C. (1991). Long term effects of sexual abuse which occurred in childhood: A review. British Journal of Clinical Psychology, 30, 117130.

Carr, A., Dooley, B., Fitzpatrick, M., Flanagan, E., Flanagan-Howard, R., Tierney, K., White, M., Daly, M., Egan, J. (2010). Adult adjustment of survivors of institutional child abuse in Ireland. Child Abuse and Neglect, 34, 477-489.

Colman, R. A., \& Widom, C. S. (2004). Childhood abuse and neglect and adult intimate relationships: a prospective study. Child Abuse and Neglect, 28, 11, 1133-1151.

Conte, J. R. \& Schuerman, J. R. (1987). Factors associated with an increased impact of child sexual abuse. Child Abuse \& Neglect, 11, 2, 201-211.

Coy, M. (2008). Young women, local authority care and selling sex: findings from research. British Journal of Social Work, 38, 1408-1424. 
SEXUAL EXPLOITATION IN YOUTH

Coy, M. (2009). 'Moved around like bags of rubbish nobody wants': how multiple placement moves can make young women vulnerable to sexual exploitation. Child Abuse Review, 18, 4, 254-266.

Craig, A.R., Franklin, J.A., \& Andrews, G. (1984) A scale to measure locus of control of behaviour. British Journal of Medical Psychology, 57, 173-180.

Cusick, L. (2002). Youth prostitution: A literature review. Child Abuse Review, 11, 230251.

Cusick, L., Martin, A., \& May, T. (2003). Vulnerability and involvement in drug use and sex work. Home Office Research Study 268. Home Office Research, Development and Statistics Directorate.

Department for Children, Schools and Families (2009). Safeguarding Children and Children from Sexual Exploitation. Supplementary guidance to Working Together to Safeguard Children. London: Department for Children, Schools and Families [DCSF].

Dimock, P. T. (1988). Adult males sexually abused as children: Characteristics and implications for treatment. Journal of Interpersonal Violence, 3, 203-221.

Dufour, M.H., Nadeau, L., and Bertrand K. (2000). Resilience factors in the victims of sexual abuse: state of affairs. Child Abuse Neglect, 24 (6), 781 - 797.

Finkelhor, D. (1987). The sexual abuse of children: Current research reviewed. Psychiatric Annals, 17, 233-241.

Finkelhor, D. (1990). Early and long-term effects of child sexual abuse: An update. Professional Psychology: Research and Practice, 21, 5, 325-330

Finkelhor, D. \& Berliner, L. (1995). Research of the treatment of sexually abused children: a review and recommendations. Journal of the American Academy of Child and Adolescent Psychiatry, 34, 11, 1408-1423

Finkelhor, D. \& Browne, A. (1985). The traumatic impact of child sexual abuse: A conceptualisation. American Journal of Orthopsychiatry, 55, 4, 530-541. 


\section{SEXUAL EXPLOITATION IN YOUTH}

Finkelhor, D., Hotaling, G., Lewis, I.A., \& Smith, C. (1990). Sexual abuse in a national survey of adult

men and women: Prevalence, characteristics, and risk factors. Child Abuse and Neglect, 14(1), 19-28.

Finkelhor, D., Ormrod, R.K, and Turner, H.A. (2007). Polyvictimization and trauma in a national longitudinal cohort. Development and Psychopathology, 1, 149-166

Fraley, R. C., Waller, N. G., \& Brennan, K. A. (2000). An item response theory analysis of self-report measures of adult attachment. Journal of Personality and Social Psychology, 78, 350-365.

Gibson, R. L., \& Hartshorne, T. S. (1994). Childhood sexual abuse and adult loneliness and network orientation. Child Abuse and Neglect, 20, 11, 1087-1093.

Harper, Z., \& Scott, S. (2005). Meeting the needs of sexually exploited children in London. Barnardos: Barkingside.

Harter, S. A.,Alexander, P. C., \& Neimeyer, R. A. (1988). Long-term effects of incestuous child abuse in college women: Social adjustment, social cognition, and family characteristics. Journal of Consulting and Clinical Psychology, 56, 1, 5-8.

Hoaglin, D. C., and Iglewicz, B. (1987). Fine Tuning Some Resistant Rules for Outlier Labelling. Journal of American Statistical Association, 82, 1147-1149.

Jago, S. (2010). Safeguarding future generations: challenging and prosecuting perpetrators. Youth \& Policy, 104, 48-61.

Jago, S., Arocha, L., Brodie, I., Melrose, M., Pearce, J., \& Warrington, C. (2010). What's going on to safeguard children and children from sexual exploitation? How local partnerships respond to child sexual exploitation. Luton: University of Bedfordshire.

Jehu, D. (1988). Beyond sexual abuse: Therapy with women who were victims in childhood. Chichester: Wiley. 


\section{SEXUAL EXPLOITATION IN YOUTH}

Kelly, L., Wingfield, R., Burton, S., \& Regan, L. (1995). Splintered lives: Sexual exploitation of children in the context of children's rights. Barnardos: Essex.

Lamb, S., \& Edgar-Smith, S. (1994). Aspects of disclosure: Mediators of outcome of childhood sexual abuse. Journal of Interpersonal Violence, 9, 307-326.

Lebloch, E. K., \& King, S. (2006). Child sexual exploitation: a partnership response and model intervention. Child Abuse Review, 15, 362-372.

Paine, M. L., \& Hansen, D. J. (2002). Factors influencing children to self-disclose sexual abuse. Clinical Psychology Review, 22(2), 271-295.

Pearce, J., Williams, M., \& Galvin, C. (2002). 'It's someone taking a part of you': A study of young women and sexual exploitation. Foundation by the National Children's Bureau.

Phoenix, J. (2002). In the name of protection: youth prostitution policy reforms in England and Wales. Critical Social Policy, 22, 2, 353-375.

Phoenix, J. (2012). Out of place: the policing and criminalisation of sexually exploited girls and young women (summary). Howard Institute for Penal Reform.

Romans, S., Martin, J., \& Mullen, P. (1997). Childhood sexual abuse and later psychological problems: neither necessary, sufficient nor acting alone. Criminal Behaviour \& Mental Health, 7, 4, 327-338.

Rosenberg, M. (1965). Society and the adolescent self-image. Princeton, NJ: Princeton University Press.

Russell, D., Peplau, L.A., \& Cutrona, C.E. (1980). The revised UCLA Loneliness Scale: Concurrent and discriminant validity evidence. Journal of Personality and Social Psychology, 39, 472-480.

Russell, D. (1996). UCLA Loneliness Scale (Version 3): Reliability, validity, and factor structure. Journal of Personality Assessment, 66, 20-40. 
SEXUAL EXPLOITATION IN YOUTH

Scott, S., \& Harper, Z. (2006). Meeting the needs of sexually exploited young people: the challenge of conducting policy relevant research. Child Abuse Review, 15, 5, 313325.

Sibley, C. G., \& Liu, J. H. (2004). Short-term temporal stability and factor structure of the revised experiences in close relationships (ECR-R) measure of adult attachment. Personality and Individual Differences, 36, 969-975.

Smeaton, E. (2013). Running away from hate to what you think is love: The relationship between running away and child sexual exploitation. Barnardos.

Stredder, K., Woolfall, K., Gray, L., \& Sumnall, H. (2009). Children and sexual exploitation: an exploration of children's workers' experiences of providing support in Merseyside. Centre for Public Health: Liverpool.

Swann, S., McNosh, D., \& Edwards, S. (1998) Whose Daughter Next? Children Abused Through Prostitution (What Works?) Barnardos: Ilford

Taylor-Browne, J. (2002). More than one chance! Children involved in prostitution speak out. End Child Prostitution, Pornography and Trafficking (ECPAT): London.

Tabachnick, B. G., \& Fidell, L. S. (2007). Using multivariate statistics: Fifth Edition. Boston: Pearson Education, Inc. / Allyn and Bacon.

Ward, J., \& Patel, N. (2006). Broadening the discussion on sexual exploitation: ethnicity, sexual exploitation and children. Child Abuse Review, 15, 341-350.

Warrington, C. (2010). From less harm to more good: The role of children and young persons participation in relation to sexual exploitation. Youth and Policy, 104.

Wolak, J., Finkelhor, D., Mitchell, K., \& Ybarra, M. (2008). Online 'predators' and their victims. Myths, realities and implications for prevention and treatment. American Psychologist, 63, 2, p111-128. 
Table 1

Sex of Participants Who Reported Being Approached Sexually

Sex of participants (n) No. approached No. who engaged in requested sexually $(\%) \quad$ sexual behaviours $(\%)$

Males (51)

$9(17.7)$

$3(5.9)$

Females (144)

$83(57.7)$

$40(27.8)$

Gender not reported (3)

$1(33.3)$

$1(33.3)$

Total

93 (47)

44 (22.2) 
Table 2

Types of Approach Made by Adults and Number of Participants Who Reported This When Under The Age of 16 Years.

Type of approach

No. approached Males Females

$(\%)$

$(\%)$

$(\%)$

Sexual suggestions made by a perpetrator

$67(33.8)$

$2(3.9)$

$64(44.4)$

or attempts to engage the individual in

sexual discussions by telephone, texts or

over the internet

Requested by a perpetrator to engage in

$57(28.8) \quad 6(11.8) \quad 50(34.7)$

sexual discussions over the internet or by

mobile phone

Being asked by a perpetrator in person to

$42(21.2)$

$2(3.9)$

$39(27.1)$

engage in sexual contact (intercourse or

other sexual contact)

\begin{tabular}{llll}
\hline Having been sent sexual/nude photographs & $35(17.7)$ & $6(11.8)$ & $28(19.4)$
\end{tabular}

or recordings by a perpetrator

\begin{tabular}{llll}
\hline A request by a perpetrator for sexual & $32(16.2)$ & 0 & $31(21.5)$
\end{tabular}

photographs or recordings to be sent by

mobile phone or the internet

\begin{tabular}{l}
\hline Had an ongoing sexual relationship with $23(11.6)$ \\
someone aged 18 or over
\end{tabular}

Being asked by a perpetrator to have sexual

$14(7.1)$

$1(2.0)$

$12(8.3)$ 
SEXUAL EXPLOITATION IN YOUTH

intercourse with another adult

\begin{tabular}{llll}
\hline Had sexual contact with a perpetrator due to & $9(4.5)$ & 0 & $8(5.6)$
\end{tabular}

fear of being harmed if they did not

Being expected to perform sexual acts

$9(4.5) \quad 1(2.0) \quad 8(5.6)$

(intercourse or other sexual contact) for

gifts (jewellery, mobile telephone, clothes,

money)

Being expected to perform sexual acts

$9(4.5)$

$9(6.3)$

(intercourse or other sexual contact) for

drugs or alcohol drinks

\begin{tabular}{llll}
\hline Being asked by a perpetrator to have sexual & $9(4.5)$ & $1(2.0)$ & $7(4.9)$
\end{tabular}

contact with another adult

\begin{tabular}{llll}
\hline Being expected to perform sexual acts & $8(4.0)$ & 0 & $8(5.6)$
\end{tabular}

(intercourse or other sexual contact) for

giving participants lifts in a car or trips

\begin{tabular}{llll}
\hline Being expected to perform sexual acts & $3(1.5)$ & $1(2.0)$ & $2(1.4)$
\end{tabular}

(intercourse or other sexual contact) for

accommodation 


\section{SEXUAL EXPLOITATION IN YOUTH}

Table 3

Means and Standard Deviations for Participant Groups Across Psychometric Measures

Group $1 \quad$ Group $2 \quad$ Group 3

Measure (no experience) (experience not $\quad$ (experience

exploited) $\quad$ exploited)

\begin{tabular}{lcccccc}
\hline & Mean & SD & Mean & SD & Mean & SD \\
\hline Locus of control & 48.2 & 8.5 & 44.7 & 6.7 & 46.1 & 7.8 \\
Self esteem & 20.3 & 6.2 & 17.8 & 5.0 & 16.9 & 6.0 \\
Loneliness & 33.8 & 4.2 & 34.9 & 4.4 & 35.3 & 4.1 \\
ECR-R Anxiety & 53.2 & 18.5 & 67.4 & 18.1 & 67.6 & 23.6 \\
ECR-R Avoidance & 78.4 & 7.7 & 82.0 & 7.7 & 78.6 & 5.9
\end{tabular}

